\title{
ESTADO E "CONVERSÃO” DEMOCRÁTICA: LEGADOS DA NOVA REPÚBLICA PARA AS POLÍTICAS EDUCACIONAIS DOS ANOS 1990
}

\author{
Antonia Almeida Silva ${ }^{2}$
}

\section{RESUMO}

Neste estudo problematizam-se as relações entre a agenda político-social da Nova República e a viabilização das reformas do Estado e da educação a partir da década de 1990. O artigo explora as relações entre as políticas sociais no plano nacional e estadual, tomando como referências, no plano nacional, a política social do governo José Sarney e, na Bahia, a política educacional do governo Waldir Pires. A hipótese que mobiliza o estudo é a de que a atitude de "agente interessado" na justiça social, assumida pelo Estado durante a Nova República, foi fundamental para a recomposição dos grupos dominantes que conduziram a transição e viabilizar a atualização do seu projeto de classe. Nesse processo, o projeto da "conversão" do autoritarismo à democratização mostra-se mais como preleção conjuntural, do que como mudança substantiva da vida política brasileira. Este argumento está baseado na assunção de que a transição brasileira, inclusive em seu momento final, guarda alguma relação com a noção de "revolução passiva" apresentada por Gramsci (1999).

Palavras chave: Estado; políticas educacionais; Nova República

\section{STATE AND DEMOCRATIC CONVERSION: NEW REPUBLIC'S LEGACY TO EDUCATIONAL POLITICS IN THE 90'S}

\begin{abstract}
In this study we analyze the relationships between New Republic's political and social agenda and the reforms of the State and of the education since the 90's. The article explores the connections between social politics in federal and state spheres by taking as references both the social politics of José Sarney's national government and the educational politics of Waldir Pires on Bahia's government. The main hypothesis is that the State in New Republica years, while pretended to be seen as an agent compromised with social justice, actually played a decisive rule in order to articulate again the ruling groups that have leaded the political transition and up to date their class project. In that process the project of conversing authoritarianism into democracy appears as an opportunistic speech rather than any substantive changing on Brazilian political life. This argument is based on the assumption that the Brazilian transition, even in its final moment, is related to what Gramsci has described with his "passive revolution" concept.
\end{abstract}

Key words: State; educational politics; New Republic. 


\section{Estado e reforma social na Nova República: feições de uma Revolução Passiva?}

A Nova República caracteriza uma etapa especial no processo de transição política brasileira. Não só era a culminância de um percurso "difícil, cheio de pequenos avanços e recuos" (Fausto, 1996, p. 489) rumo ao regime político democrático, mas também um momento que se diferenciava pela tônica reformista assumida pelos poderes constituídos, particularmente o executivo. Mais que um acerto de contas político, a Nova República prometia deflagrar um processo de reparação da dívida social brasileira, através de redistribuição de rendas e combate à pobreza. No texto do discurso de posse de Tancredo Neves isso se manifesta tanto no ideário nacionalista, quanto nas promessas de modernização e reformas, como registra Camargo (1998, p. 38):

[...] afirma-se um ideário nacionalista - herança da era de Vargas voltado para a integração Estado-Nação, para a retomada do desenvolvimento econômico com autonomia nacional. Ao mesmo tempo, o presidente enumera medidas urgentes de expansão e consolidação do setor moderno, tais como a reforma administrativa e o investimento prioritário em ciência e tecnologia, ao lado de uma política de reformas voltadas para a redistribuição de rendas e o incisivo combate à pobreza. Ambas as frentes - de modernização e de reformas - seriam acompanhadas ou precedidas por medidas políticas de liberalização liberdade de imprensa, restauração do Poder Legislativo, valorização dos partidos políticos - e de redemocratização e expansão da cidadania: convocação da Constituinte, legalização dos partidos de esquerda, voto do analfabeto e eleições gerais e diretas em todos os níveis, inclusive para a Presidência da República, prevista para 1988 (grifos meus).

Essas promessas não estavam no discurso de Tancredo por acaso. Elas se constituíram em peças-chave para diferenciar o novo governo dos governos dos militares. Essa diferenciação se construiu muito cedo dentro do $\mathrm{PMDB}^{3}$ que, à frente da Aliança Democrática $^{4}$, passou da oposição para o governo com a eleição do primeiro presidente civil pós-1964. Como observa Skidmore

O PMDB sempre atacou as políticas dos governos militares pelo fato de supostamente aumentarem as enormes desigualdades econômicas e sociais. O manifesto peemedebista de 1982 apresentava os princípios e as prioridades com que pretendia governar, descrevendo o Brasil como "um dos campeões mundiais de concentração da renda e da riqueza", apesar de estar classificado como uma das maiores potências industriais "entre as economias de mercado" (SKIDIMORE, 1988, p. 546).

Uma vez assumida a presidência, portanto, nem o PMDB nem os seus aliados, organizados na Aliança Democrática, poderiam abandonar o discurso que lhes fizera chegar ao governo, ao menos de imediato. Mesmo depois da posse de José Sarney a implementação de medidas de enfrentamento das questões sociais continuou em evidência, mobilizando algum esforço dentro do governo. Assim foi que o trabalho produzido pela Comissão do Plano de Ação do Governo (COPAG) foi mantido por Sarney. Essa Comissão, incumbida por Tancredo Neves para identificar os mais importantes problemas econômicos que o novo governo teria que enfrentar e as alternativas para melhorar a igualdade econômica, recomendava em seu relatório a implantação de um programa de emergência para ajudar os mais pobres. 
Incluía a distribuição de leite subsidiado a crianças de famílias de baixa renda juntamente com programas de obras públicas geradoras de empregos, como construção de moradias em regime de emergência e um plano de saúde para execução imediata nas áreas mais atrasadas (SKIDIMORE, 1988, p. 553-554).

Sem entrar no mérito dessas orientações e considerando que elas tiveram duração efêmera como política de combate à pobreza, a alusão a essa iniciativa serve como ilustração do modo como esse governo se relacionava com as políticas públicas de natureza social. Ao lado desse exemplo, outra investida importante se deu em agosto de 1985, com a constituição de novo grupo de estudos para preparar um relatório sobre problemas sociais brasileiros, com vistas a uma ordenação social mais equitativa. A comissão, coordenada pelo professor Hélio Jaguaribe, propôs em seu relatório, apresentando em maio de 1986,

[...] uma estratégia de quinze anos para elevar os padrões de vida dos brasileiros ao nível dos vigentes na Espanha ou na Grécia. Para isso era necessário aumentar substancialmente os investimentos em programas sociais, inclusive a reforma agrária, de par com uma taxa média de crescimento econômico de 6 por cento. O relatório defendia uma estratégia por áreas dentro do Plano Plurianual de Desenvolvimento Social. O presidente Sarney aceitou o relatório e imediatamente prometeu 12 por cento do PIB para programas de bem-estar social (SKIDIMORE, 1988 , p. 556) ${ }^{5}$.

Esses dados ilustram o quanto a Nova República, como transição de uma direção política civil-militar à direção civil, também nomeada de democracia, trabalhou na construção de uma identidade que lhe associava a um projeto de mudanças não só de natureza política, mas também de natureza econômico-social.

Contudo, cabe perscrutar a natureza dessas mudanças e suas possíveis relações de continuidade e ruptura com as forças dominantes. Nota-se que se antes o Estado estava marcado pelo autoritarismo, pela repressão e pelo tecnocratismo, agora ele se projetava pelo discurso da reordenação e da integração dos segmentos sociais e políticos marginalizados. Esse deslocamento insinuava certa flexibilização na organização estatal em relação ao modelo anterior, num movimento de maximização do sistema representativo governamental.

As retóricas da participação popular e da prioridade aos projetos sociais se apresentam como interesses universais da sociedade civil, neste contexto, o Estado passa a figurar como representante dos interesses coletivos. Esta roupagem tendia a identificar o Estado como

[...] um agente profundamente interessado em fazer "justiça social", em diminuir as desigualdades e, ao mesmo tempo, "recuperar a participação das bases" na definição e gestão dos programas governamentais que lhes são destinados (Germano, 1994, p. 251).

O Estado, então, passava a figurar como mediador dos diversos interesses que se apresentavam na cena política, administrando um amplo e complexo movimento de negação do regime militar, sem, contudo, confrontá-lo. Longe da distinção das 
ambiguidades de classes que davam contornos às tensões vividas pelos setores organizados, o discurso oficial e dos setores historicamente dominantes fizerem da democratização o pilar de um suposto consenso nacional e neste jogo político duas questões de fundo se imbricam para a compreensão do movimento em questão: de um lado a noção de Estado e, complementarmente, as formas de organização política na arena das lutas de classe. No sentido gramsciniano a concepção de Estado supõe a diferenciação entre o Estado em sentido estrito e o Estado em sentido amplo ou integral. Em sentido estrito o Estado refere-se a exército, polícia, administração, burocracia (sociedade política), enquanto em sentido ampliado Estado refere-se à função adaptativo-educativo, por meio da construção da direção intelectual (sociedade civil). Neste sentido, "Por 'Estado' deve-se entender, além do aparelho de governo, também o aparelho 'privado' de hegemonia ou sociedade civil". (GRAMSCI, 1999, p. 254-255).

Não obstante esta distinção, a difusão do sentido clássico ou estrito do conceito aparece na cena nacional com feições universais e como tal acaba por jogar um papel ideológico que se beneficia da confusão entre Estado e governo para aplacar as próprias tensões entre e intra classes, como ademais se observa no período em foco. Como assinala Fontes (2006, p. 2011): "Gramsci aprofunda o tema das formas de organização, e se sua reflexão incide diretamente sobre a organização da dominação, o faz já incorporando o processo da luta de classes e de conquistas populares no âmbito do Estado capitalista". Nesta compreensão o Estado não se restringe a arena da sociedade política, mas envolve a sociedade civil em suas facetas não só diferentes, mas antagônicas. Ademais, como acrescenta Fontes (2006, p. 2011):

Em Gramsci, o conceito de sociedade civil procura dar conta dos fundamentos da 'produção social, da organização das vontades coletivas e de sua conversão em aceitação da dominação, através do Estado'. O fulcro do conceito gramsciniano de sociedade civil - dos aparelhos privados de hegemonia - remete para a organização (produção coletiva) de visões de mundo, da consciência social, de 'forma de ser' adequadas aos interesses do mundo burguês (a hegemonia) ou, ao contrário, capazes de opor-se resolutamente a esse terreno dos interesses (corporativo), em direção a uma sociedade igualitária ('regulada') na qual a eticidade prevaleceria (o momento ético-político da contra-hegemonia).

Perceber as formas de organização na chamada Nova República, portanto, é chave importante para a compressão do período e das tensões em disputa, incluindo os jogos que mais conformam os interesses dominantes do que os conflita. São exemplares disto as articulações políticas que emolduraram as eleições para os governos estaduais e municipais, no primeiro quinquênio da década de 1980, e no seu epicentro o processo Constituinte.

Em torno da Constituinte fortaleceram-se as expectativas de reconstrução nacional, alimentando um clima de entusiasmo e de esperanças extraordinários ${ }^{6}$. Simultâneo a isso a tensão entre conservação e mudança trouxe as forças políticas para um campo emblemático de disputas, em que representantes de setores historicamente conservadores se revestem de feições brandas, ou como define Dreifuss (1989), busca a construção de uma Constituinte "mansa". Como expressão disso o Pensamento Nacional das Bases Empresariais (PNBE) ganhou corpo em 1986 como um movimento de união dos empresários. Como flagrou Dreifuss nas diversas expressões da citação abaixo, retratando o pensamento de setores empresariais no contexto em tela: 
Questionou-se, portanto, a estrutura representativa do empresariado, seu formato e métodos. O que diferencia a Fiesp do PNBE "é a ação prática, a tática. $\mathrm{O}$ estilo mudou radicalmente", garantiu um dirigente da nova entidade. Ou, como diria Bruno Nardini: "As bandeiras são as mesmas, a diferença está no processo". Grajew seria ainda mais claro: "A divisão no empresariado, hoje, não é mais entre grandes e pequenos e sim entre forças conservadoras e democráticas". Com ele, concorda até hoje o empresário Emerson Kapaz, presidente do Sindicato das Indústrias de Instrumentos Musicais e Brinquedos do Estado de São Paulo e um dos dirigentes do PNBE: "As iniciativas de organização dos empresários, fora das instituições tradicionais, são muito bem vistas, sobretudo numa conjuntura de refluxo dos movimentos de massa". E mais: "Siglas como UDR e PNBE vão atrair pessoas que se afinem ideologicamente com elas, rompendo os limites corporativos de sindicatos e federações" (DREIFUSS, 1989, p. 131).

Como expressão dessa movimentação, a Constituição de 1988 traduziu os conflitos e sua aura "mansa" em termos de resultados, sintetizando as contradições do processo de redemocratização brasileira captadas no fragmento acima. No plano social, particularmente em relação à educação, as ações da Nova República, a despeito de sua aura reformista, são inexpressivos como promotores de justiça social. Como assinala Kuenzer:

Na Nova República, não se chegou a ter um documento de planejamento
que refletisse as demandas populares que deram sustentação à nova
aliança. Particularmente no setor "Educação", o documento "Educação
para todos" era uma tentativa de satisfazer a este imperativo, mas também
não chegou a orientar a elaboração de programas de ação. Pelo contrário,
é a partir desta época que o MEC passa a se relacionar diretamente com
os municípios, justificado pela necessidade de "descentralização" como
imperativo de democratização. A partir daí, o MEC configurou-se mais
como agência repassadora de recurso do que como articulador e
viabilizador das demandas educacionais, em todos os níveis. Assim,
substitui-se o centralismo tecnocrático pela fragmentação com fins
clientelistas. Os resultados continuaram os mesmos, ou seja, a drenagem
de recursos para ações nem sempre justificáveis, aprovadas pelo
privilegiamento das relações políticas como critério de distribuição de
recursos (1996, p. 82).

Certamente que as políticas públicas, ao menos em tese, são expressões das estratégias de governo para solucionar problemas públicos. Contudo, as ações engendradas e as estratégias adotadas no âmbito de cada governo são pautadas por princípios, isto é, indicam escolhas políticas que se refletem no beneficiamento de alguns setores mais do que outros (Palumbo, 1989). Assim, tanto podem mediar mudanças que favoreçam a conjuntos sociais mais amplos e historicamente alijados de benefícios sociais (como educação), quanto se limitarem a atualizar velhos padrões, sem impactos significativos na realidade daqueles. É o caso das políticas educacionais assumidas pela Nova República e isto, para além dos possíveis limites administrativos, deve ser lido no movimento mais amplo de mútua implicação entre os direcionamentos para a área e os interesses dos 
setores organizados com capital simbólico e material para capitanear a direção política da cena política brasileira no contex to em tela.

Neste marco faz-se mister não minimizar o fato de que a transição política fomentada na Nova República engendrou um movimento de abertura política que, ao assegurar a manutenção do controle do Estado pelas mesmas forças que produziram o regime militar, simultaneamente mediou o "plano de produção" dessas forças e a sua recomposição.

O movimento de reorganização do poder pode ser observado no plano nacional desde a aparente indefinição de rumos experimentada no governo símbolo da Nova República, José Sarney, até a rejeição de formas antigas de organização política de setores do empresariado, como evidencia Dreifuss (1989), abrindo espaços para que novas siglas se confundam com projetos novos.

Embora esse papel assumido pelo Estado não seja um dado novo no Brasil do séc. XX, que alterna o paternalismo e a repressão no enfretamento dos conflitos de classe ${ }^{7}$, a atitude de "agente interessado" na justiça social não pode ser lida como um dado menor. Nessa manobra a transição branda foi preparando articulações que mais de perto evidenciam aproximações com a noção de "revolução passiva" apresentada por Gramsci.

A "revolução passiva" refere-se a um elemento no campo político que corresponde aos movimentos da classe hegemônica, por intermédio da intervenção legislativa do Estado e da organização corporativa, para introduzir modificações que assegurem o "plano de produção" dessa classe (Gramsci, 1999).

Esse conceito, empregado por Gramsci para compreender o contexto italiano do século XIX, envolve dois temas relevantes que permitem pensar o contexto brasileiro: o lugar estratégico da intervenção do Estado a) na legislação e b) no tempo da reorganização corporativa da classe hegemônica. No quadro concreto das relações italianas, diz Gramsci,

[...] esta pode ter sido a única solução para desenvolver as forças produtivas da indústria sob a direção das classes dirigentes tradicionais, em concorrência com as mais avançadas formações industriais de países que monopolizam as matérias-primas e acumularam gigantescos capitais. Que um tal esquema possa traduzir-se em prática, e em que medida e em que formas, isto tem um valor relativo: o que importa, política e ideologicamente, é que ele pode ter, e tem realmente, a virtude de servir para criar um período de expectativa e de esperanças, notadamente em certos grupos sociais italianos, como a grande massa dos pequenos burgueses urbanos e rurais, e, conseqüentemente, para manter o sistema hegemônico e as forças de coerção militar e civil à disposição das classes dirigentes tradicionais (GRAMSCI, 1999, p. 299-300).

No caso brasileiro tanto a reorganização legislativa, quanto a reordenação corporativa se deram no clima de suposta pacificação das relações políticas e de abertura dos diferentes setores para proporem siglas organizacionais. Estas emergiram como sinal de renovação e ruptura com o passado autoritário. A transição sem revanche, a Constituinte "branda" e a proliferação de organizações sociais revestidas de propósitos democráticos podem ser lidos como parte do time que materializa a "revolução passiva" engendrada para consubstanciar a rearticulação do plano de produção da classe dominante e a materialização da sua hegemonia.

Nesse período, não por acaso, embora alguns países já implementassem políticas impopulares, com prioridade para a estabilidade monetária e a contenção do orçamento, 
alimentavam-se no Brasil expectativas em torno de políticas de expansão de direitos. Nos bastidores da política, porém, a situação era controversa.

A atuação das forças dominantes na Constituinte é um exemplo disso, como conseguiu mostrar Dreifuss (1989) ao explicitar nuanças e estratégias encetadas por diferentes segmentos empresariais para controlar a elaboração da Carta de 1988. Fica claro nesse estudo que as conquistas organizacionais dos setores populares ainda eram tidas como uma grande ameaça. Como veio a se confirmar posteriormente, não era a democracia em si que tirava o sono da classe dominante nesse período, mas sua adequação e reinserção à nova configuração do capitalismo mundial. Dreifuss percebe esse processo e o documenta em seu trabalho, dizendo que:

Apesar da indiferença de muitos, estava em curso um diligente e apressado trabalho de reestruturação política do empresariado, que dava a medida do empenho e combatividade de certas elites dispostas a enfrentar os novos desafios. Assim, o brasileiro descobriu na envelhecida Nova República uma classe empresarial que passara a se envolver na política de forma aberta e vocal - mas sem desdenhar meio e métodos mais subreptícios -, numa percepção da necessidade de reorganizar-se política e ideologicamente, o que requeria a articulação de um programa de governo, que, por sua vez, demandava preparação político-operacional. Em outras palavras: os empresários se preparavam para defender não somente a existência do atual regime e sistema, mas a sua readequação, desenvolvimento e estabilidade, assim como a sua reinserção ou reboque na nova configuração transnacional. Tal empreitada, porém, estava comprometida na origem, pois os reajustes propostos esbarravam, mais uma vez, nos limites do realinhamento conservador, da convergência elitista e do transformismo institucional (DREIFUSS, 1989, p. 45).

Logo, estava em questão não só a culminância da transição para a democracia, mas um processo que recolocava em pauta o poder, mexendo por dentro nas formas de organização e atuação da classe dominante. As contumazes reações à organização e à mobilização populares, desta feita, não se dariam pelas vias de costume: os golpes e os quase golpes relatados por Oliveira (2001) foram postos de lado, pois talvez não coubessem ou não tivessem como ser sustentados.

A aproximação com o cenário estadual nos permite ver ainda mais de perto esse movimento. Na Bahia observou-se que as lideranças políticas do grupo liderado por Antonio Carlos Magalhães (ACM), também nomeado carlistas/carlismo, souberam tirar proveito desse cenário, assumindo uma oposição agressiva ao governador que ascendera num momento de entusiasmo, quando as contradições da democratização negociada ainda não se haviam mostrado plenamente. Cheguemos mais perto!

\section{Waldir Pires e a expressão estadual da Nova República: que mudança ele representa?}

Waldir Pires era um nome simbólico no contexto da renovação aspirada na transição. Sua trajetória é resumida por João Gomes nos seguintes termos:

[...] sempre se colocara a serviço das causas populares e de defesa dos interesses do Brasil. Desde cedo envolveu-se em posições nacionalistas, 
pregando uma política externa soberana e independente. Em inícios da década de 40, engrossara a agitação cívica deflagrada para forçar o governo Vargas a formar ao lado dos aliados contra a Alemanha nazista, subindo aos palanques armados nas praças públicas para defender as liberdades ameaçadas pelas ditaduras. Lutara pela encampação da Bond and Share na Bahia e em defesa das riquezas nacionais, participando dos movimentos em prol do petróleo brasileiro, que culminaram com a criação da Petrobrás por Getúlio Vargas. Ao lado disso, mantivera-se fiel a João Goulart até o fim (GOMES, 2001, p. 343).

Na Nova República, Waldir Pires compunha o governo assumindo o cargo de ministro da Previdência Social. Nessa função, destacara-se logo como um dos cinco novos ministros que "foram banidos pelo governo militar com cassação de seus mandatos ou a perda dos seus direitos políticos ou ambas" (SKIDMORE, 1988, p. 497) ${ }^{8}$. Tratava-se, portanto, de uma referência política com inserção nacional e que, à frente do governo do estado, representava também a vitória do projeto político-econômico-social da Nova República.

Em 15 de março de 1987, Waldir Pires e Nilo Coelho assumiram o governo da Bahia dentro de um clima de muitas expectativas, com o slogan "governo democrático da mudança". A forte associação entre a trajetória política de Waldir Pires e os discursos de justiça social, democracia e Estado voltado para o interesse público credenciaram esse governo como alternativa para inaugurar uma nova fase na vida político-governamental baiana. Waldir Pires assumiu o governo afirmando a construção de um "tempo novo" e definiu seu governo como o governo da liberdade, conclamando a todos a ajudar a construir e organizar "uma sociedade em que as liberdades e os direitos fundamentais do homem sejam inegociáveis e onde o bem-estar das populações e de cada indivíduo seja plenamente assegurado" (PIRES, 1987, p. 14-16).

Com esse espírito, ele assentaria sua plataforma de governo sob as bandeiras da transparência e da justiça, preconizando a moralização e a eficiência dos serviços prestados pelo Estado como fundamentos da sua administração.

Para a Secretaria da Educação, nomeou Mariaugusta Rosa Rocha. A secretária não anunciou de imediato um plano para a educação; suas ações foram no sentido de assegurar algumas condições básicas de funcionamento da rede estadual de educação. Logo no primeiro dia de governo, Waldir Pires e a secretária Mariaugusta visitaram a Escola Parque $^{9}$ e denunciaram a depredação desse símbolo da educação pública moderna, anunciando que o governo não iria iniciar novas obras enquanto não recuperasse o patrimônio público escolar.

O Programa SOS Escola, anunciado em dez dias do governo, foi colocado como plano de emergência para salvar a escola pública. Este programa foi centralizado no então Departamento de Ensino de $1^{\circ}$ e $2^{\circ}$ Graus e desenvolvido por uma equipe de assistência pedagógica e pessoal de construção e reparo de infraestrutura.

Ainda no mês de março o governo anunciaria um programa emergencial de ação, o Programa de 100 Dias, no qual ratificava os compromissos com a mudança e definia a área social como prioridade para elevar as condições de vida do povo. Para a educação, o programa previa dez frentes de atuação do governo, a saber:

1- Recuperar a Escola Parque Anísio Teixeira - com capacidade para 7.000 alunos - em suas instalações físicas e equipamentos essenciais, assegurando, no período deste Programa, o funcionamento de pelo menos um de seus núcleos. 
2- Recuperar pelo menos 100 escolas, no período do Programa, antes da construção de qualquer nova unidade.

3- Criar o programa "SOS Escola", mobilizando a comunidade para a formação de núcleos com finalidade de executar pequenos reparos de urgência nas escolas da rede estadual - faxina geral, pintura, trabalhos de pedreiro, serviços de carpintaria.

4- Deflagrar a Campanha contra o Analfabetismo, com ênfase na escolarização básica, além de ampliar a oferta de classes noturnas regulares.

5- Incrementar - suprindo as deformações atuais - os programas de merenda escolar e saúde via escola, de material escolar, de distribuição do livro didático, dentre outros.

6- Implantar o projeto piloto "Sábado e Domingo na Escola", visando ao atendimento de adultos em programas integrados de educação geral, profissionalização e lazer.

7- Lançar programas de educação à distância, via rádio e televisão.

8- Criar o programa de desenvolvimento infantil, com apoio das Nações Unidas, voltado, inicialmente, para crianças carentes da comunidade negra, visando à preservação e ao desenvolvimento de seus valores culturais.

9- Cadastrar todos os servidores da Secretaria de Educação para promover o remanejamento adequado, com prioridade para o aumento do número de professores em salas de aula.

10- Programar concursos públicos, para realização ainda este ano, na área da educação de $1^{\circ}$ e $2^{\circ}$ graus (PROGRAMA DE 100 DIAS, 1987, p. 4-6).

Essas dez frentes passariam ao largo de um diagnóstico mais abrangente sobre a situação da educação no estado. Dessa forma, repetia-se uma lista recorrentemente invocada pelos governos, sem trazer novidades que expressassem esforços de edificação de uma nova prática de gestão.

Impulsionado pela pressão dos professores, desenhou-se nesse período também a discussão de alguns temas tais como: a) processo de escolha de diretores nas escolas; b) rediscussão do Plano de Carreira do Magistério do Nível Superior, uma vez que Waldir Pires negava-se a efetivar o plano aprovado pelo governador João Durval Carneiro, seu antecessor; c) Plano de Carreira dos Professores do Nível Básico.

No mesmo ano, foi aprovada a Lei $n^{\circ} 4.694$, que estruturou o Plano de Carreira do Magistério de $1^{\circ}$ e $2^{\circ}$ Graus e que foi regulamentada pelo Decreto $n^{\circ} 506 / 87$. Tais ações, contudo, ficavam bem aquém das expectativas geradas. Assim, paralelamente ao desgaste do governo da Nova República, o governo do estado não conseguia operar as mudanças anunciadas, pelo menos não no ritmo esperado. O distanciamento das expectativas de mudanças, geradas durante as eleições de 1986, e o acúmulo de frustrações, ao longo do primeiro ano de governo, vão se explicitando aos poucos, como revela o dossiê produzido pela APLB (Sindicato dos Trabalhadores em Educação do Estado da Bahia). Este documento, traçando um diagnóstico da situação da educação no estado, denunciava que:

A educação na Bahia sempre foi tratada com descaso e desprezo por todos os governantes do período autoritário. As esperanças dos baianos reacenderam-se com a instalação do Governo Democrático que, juntos, conquistamos, inclusive com expressivo apoio dos professores baianos. Um ano depois, no entanto, sobra frustração, a angústia toma conta da Educação no Estado. 
Estamos no início de maio de 1988 e a maioria das escolas na rede estadual ainda não teve iniciadas as aulas, regularmente; por absoluta e incompreensível falta de segurança muitas escolas foram depredadas, há falta de carteiras na maioria delas, grande parte sequer dispõe de material escolar e administrativo. Os professores foram traídos. O Plano de Carreira, conquistado a duras penas e após várias greves, diminuiu salários, penalizou a maioria, extinguiu direitos adquiridos. Vagas foram aumentadas sem qualquer planejamento e há superlotação de alunos em grande parte das escolas, o que prejudicará sensivelmente a qualidade do ensino e do aprendizado no início das aulas que ninguém sabe quando ocorrerá, regularmente (APLB, 1985, p. 1).

Embora no setor da educação a insatisfação com o "governo da mudança" tenha-se manifestado já em 1988, com o citado documento da APLB, surgia em 1990 uma nova mobilização pró-mudanças na educação. Por meio de uma iniciativa do governo, vários setores envolvidos com a educação na Bahia foram convidados a discutir e formular um plano de educação, que resultou na proposta do Plano Decenal de Educação do Estado da Bahia (PLANDEBA).

\section{PLANDEBA: o último suspiro do discurso social na educação}

O PLANDEBA foi formatado em dois volumes sobre a educação na Bahia: um, contendo o diagnóstico da realidade educacional baiana (SECRETARIA DE EDUCAÇÃO DO ESTADO DA BAHIA, 1988), e o outro, o Plano propriamente (SECRETARIA DE EDUCAÇÃO DO ESTADO DA BAHIA, 1990), além de um anexo com as contribuições dos grupos de trabalho que atuaram durante a Conferência Baiana de Educação, espaço em que o documento foi discutido e recebeu emendas de diferentes setores sociais. Após sua discussão, o documento foi encaminhado ao então governador Nilo Coelho, para conhecimento do processo, e ao Conselho Estadual de Educação, para que exarasse parecer conclusivo sobre o plano, como relata correspondência do então secretário da Educação Joir Brasileiro.

Convém assinalar que o referido plano começou a ser elaborado em atendimento aos dispositivos constitucionais. No âmbito da Constituição Federal, os artigos 205 e 214, que tratam, respectivamente, do direito à educação e da elaboração do Plano Nacional de Educação e, no âmbito da Constituição do Estado da Bahia, o artigo 250, que indica o estabelecimento do Plano Estadual de Educação. Portanto, a iniciativa de que estamos tratando não estava relacionada às orientações da Conferência Mundial de Educação para Todos, realizada na Tailândia em março de 1990, e promovida por UNESCO, UNICEF, PNUD $^{10}$ e Banco Mundial, a qual deflagrou a elaboração do Plano Decenal de Educação para Todos, aprovado no Brasil em 1993.

O PLANDEBA havia sido encaminhado ao CEE em 27 de abril de 1990, por meio do Of. GAB no 609, conforme registra o próprio Parecer do CEE. Se aprovado fosse, teria sido o primeiro plano de educação elaborado fora do marco tecnicista que prevaleceu durante o regime militar, pois, além de refutar tal paradigma, o PLANDEBA surgia como expressão do discurso social entabulado na Nova República. O plano foi analisado e aprovado pelo Conselho Pleno do Conselho Estadual de Educação em 21 de janeiro de 1991, pelo Parecer CEE no 13, o qual teve como relator o Conselheiro Luiz Felippe Serpa. 
Traduzindo toda a rejeição ao regime militar e todo o entusiasmo e expectativa da redemocratização do país, em seu parecer o professor Felippe Serpa declarava que o pressuposto para a implantação do plano deveria ser a superação da ideologia de planejamento do Estado autoritário pela do Estado democrático. Diz o relator:

Cremos que a concepção mais significativa da relação entre Educação e Estado democrático é sintetizada nas palavras de Anísio Teixeira, as quais assumimos como paradigma:

"As relações, portanto, entre o Estado Democrático e a Educação são relações intrínsecas, no sentido de que a Educação é a condição sine qua non da existência do Estado Democrático" (CONSELHO ESTADUAL DE EDUCAÇÃO, 1991, p. 6).

O parecer reconhecia a importância do PLANDEBA para a Bahia e ressaltava, entre outras indicações, que seriam necessários grandes esforços para que, no prazo de dez anos, se pudesse transformar o perfil quantitativo e qualitativo do quadro da educação pública naquele estado. Dentro do diagnóstico apresentado no próprio PLANDEBA, o parecer realçava que:

Sob o ponto de vista quantitativo, teremos de colocar na escola cerca de 1.000 .000 crianças e jovens até o ano 2.000, escolarizar 2.500.000 pessoas analfabetas, o que significa um aumento de matrículas na rede pública de 100.000 crianças e jovens ao ano e 250.000 analfabetos também ao ano, requerendo salas de aula, professores e material escolar.

Se acrescentarmos as preocupações com a pré-escola, o ensino médio e o ensino superior, procurando-se aumentar as porcentagens de atendimento, a empreitada tem dimensões que exigem um investimento maciço do Estado e da Sociedade.

[...] Sob o ponto de vista qualitativo, o perfil de matrículas da rede pública -predominantemente nas três primeiras séries do $1^{\circ}$ grau - , o atraso escolar, a repetência, a evasão, a qualidade da formação do professor, as condições físicas das unidades escolares e a qualidade do material escolar, são outros aspectos desafiadores para qualquer Plano de Educação, os quais deverão estar explicitados claramente ao nível das prioridades e das estratégias de ação. (CONSELHO ESTADUAL DE EDUCAÇÃO, 1991, p. 8).

Esse diagnóstico dá, em certa medida, uma dimensão de que os desafios a serem enfrentados não poderiam ser resolvidos de uma vez, nem no período de apenas uma gestão e muito menos à revelia do debate sobre as competências/responsabilidades das esferas administrativas, principalmente do Estado.

Embora as expectativas geradas em torno do plano fossem favoráveis, ele não chegou a ser implementado. O governo que sucedeu a gestão Waldir/Nilo Coelho, a partir de 1991, optaria por não levá-la à frente. A esperança depositada no "governo da mudança" foi substituída pela ofensiva da oposição, sob o comando de ACM. Este, desde os primeiros meses do governo Waldir Pires, partiu para o ataque e, realinhando seu discurso político para parecer mais democrático e menos conservador, vestiu a aura de eficiência administrativa, contra a "moleza" de Waldir.

João Gomes afirma que o ministro das Comunicações, ACM, esmagado nas urnas, armou-se de um "formidável porrete tecnológico para agredir noite e dia o governo da mudança” (GOMES, 2001, p. 337) e fez dessa prática um recurso para beneficiar seus 
aliados e manter-se no poder. Segundo ele, a cruzada de desmoralização do governo não tinha limites.

\begin{abstract}
Não contente em atacar a administração como um todo, o ministro se voltava contra a pessoa do governador para humilhá-lo publicamente. Da mesma maneira como já havia procedido diante das câmaras da sua TV, numa entrevista concedida aos jornalistas Josias de Souza e Mauro Lopes, da Folha, em 6 de dezembro de 87, perguntado sobre se Waldir fazia ameaças para obter resultados nas votações da Constituinte, respondeu: "Porque ele fala um pouco mais fino ou mais leve, não quer dizer que não faça ameaça". Naquela altura dos acontecimentos, aludindo ao hábito de Waldir de viajar para os vários Estados (e sobretudo para Brasília), a fim de manter contatos políticos, seu jornal afirmava que "o governador era abelha: voava, voava e fazia cera". Simultaneamente, seus correligionários pichavam toda a cidade com estes dizeres: "Chega de moleza: queremos o Malvadeza". Não lhes causava constrangimento sequer invocar tão desprimoroso apelido - "Toninho Malvadeza" - para desmoralizar o adversário. (GOMES, 2001, p. 353)
\end{abstract}

De fato, o ministro estava permanentemente em evidência nos diversos meios de comunicação e invariavelmente tecendo críticas ao governo do Estado, tachando-o de incapaz, indeciso e até mesmo de fazer da máquina pública um aparelho de usufruto pessoal, como no caso da denúncia dos supostos banquetes organizados por Waldir Pires na Governadoria.

Se a tônica social do governo da Nova República era um diferencial, no "governo democrático da mudança" isso era a base do discurso e fora destacado como prioridade absoluta. Suas ideias permaneciam fiéis ao nacional-desenvolvimentismo, e talvez isso se tenha constituído em sua fortaleza, num primeiro momento, e em sua fraqueza, num contexto em que tal projeto já não empolgava mais os setores dominantes. Assim, embora se constituísse no discurso dominante da transição, o discurso de Waldir Pires já não encontrava sustentação para se impor ao carlismo.

No início de 1989, Waldir Pires afastou-se do governo do Estado para concorrer à vice-presidência da República, na chapa encabeçada por Ulysses Guimarães (ambos pelo PMDB). De 1989 a 1991 o governo do estado foi assumido por Nilo Coelho, quando a cruzada da desmoralização foi intensificada mediante as denúncias de improbidade administrativa. Enfim, os quatro anos do que seria o governo de mudanças profundas no exercício do poder, mediante o desenvolvimento democrático cristalizado no aumento do padrão de vida e da capacitação do conjunto da população, foram maculados como um período de retrocessos econômico, político, social e cultural.

Em relação à educação, o quadro era particularmente degradante. Todos os jornais e a TV com maior inserção no Estado noticiavam o caos em que estava enredado o sistema estadual de educação.

Professores, carteiras, merenda e material escolar estão ausentes em inúmeras escolas do interior da Bahia, mantidas pelos governos estadual e municipais. Milhares de alunos estão fora das escolas porque não conseguiram matrículas ou os colégios onde se matricularam estão em reformas. Na zona rural, professoras leigas, diante da necessidade de manter a disciplina, agravada pela fome das crianças, apelam para a tradicional palmatória e outros castigos. Mas elas também são castigadas 
pelos salários aviltantes de até Cr\$ 600 mensais. (DEFICIÊNCIA DA EDUCAÇÃO GERA PROTESTO DE ALUNOS, 1990, p. 3).

A partir de setembro de 1990, o sistema estadual de educação básica praticamente parou, chegando ao ponto de o Conselho Estadual de Educação manifestar-se publicamente em matéria paga divulgada pelo jornal Tribuna da Bahia, em 23 de novembro de 1990, reconhecendo a situação da escola pública na Bahia como gravíssima e recomendando à Secretaria de Educação do Estado da Bahia algumas medidas para a viabilização do ano letivo de 1990, entre as quais:

- providências urgentes quanto aos meios necessários ao cumprimento das alternativas aprovadas, dentre elas o provimento do número de professores imprescindíveis para o funcionamento regular de cada escola. - constituição imediata de Comissão Emergencial de Inspeção, ampliando o setor competente com pessoal remanejado de outros setores do nível central do sistema, bem como das SUREDs [Superintendências Regionais de Educação], se necessário, com o objetivo específico de acompanhar as propostas de conclusão do ano letivo de 1990, organizadas pelas escolas a partir das alternativas aprovadas por este Parecer, encaminhando Relatório de cada UE para este Conselho.

- oferta, por parte do Departamento de Educação Continuada, de exames supletivos, com publicação de resultados até 31.12, possibilitando, aos alunos que o desejarem, a conclusão do seu curso, sobretudo quanto aos do $2^{\circ}$ grau, com vistas aos exames vestibulares para o ensino superior. (CONSELHO ESTADUAL DE EDUCAÇÃO, 1990).

Nas eleições de 1990, ACM saiu vitorioso. Ele, que já havia sido governador do Estado por duas vezes, mas em nenhuma delas tinha sido eleito, enfim conseguia a consagração das urnas. A eleição de ACM se deu num contexto de descrédito do governo do estado e coincidiu com um período de intensificação da cruzada antidesenvolvimentista e pró-social-liberalismo, deflagrada desde a eleição do presidente Fernando Collor de Mello, um ano antes das eleições para governador. Assim, enquanto o país erigia à presidência, em 1990, um quadro político supostamente novo e condizente com o projeto de renovação que o período encerrava, a Bahia, em 1991, voltava a ser comandada pelas forças políticas antes rejeitadas e historicamente vinculadas aos setores econômicos dominantes. Não há como passar despercebido nesse processo que, se a atuação de ACM na Eletrobrás foi o salto qualitativo que faltava para sua confirmação como ator de confiança dos grupos políticos dominantes, não foi menos importante a sua "passagem" pelo Ministério das Comunicações.

Por outro lado, não se pode perder de vista que o próprio afastamento do governador Waldir Pires para concorrer à vice-presidência tenha dado a seus adversários mais munição para o combate do "governo da mudança". Nilo Coelho, um dissidente do carlismo, além de não gozar do prestígio político de seu companheiro de chapa, não tinha o manejo político que o cargo exigia. A troca de acusações e xingamentos entre ele e ACM tornou-se uma constante. Ressentimentos de antigos aliados!

Convém lembrar que, excetuando-se dois intervalos - 1975-1979 e 1987-1991 -, desde 1971 o carlismo (certamente o que ele representa politicamente) se manteve à frente do governo do estado. Não obstante, só a partir da década de 1990 ele conseguiu a hegemonia almejada e obteve sucessivas vitórias até as eleições de 2006, quando sofreria 
uma derrota na disputa do cargo para governador, com a ascensão do governo do Partido dos Trabalhadores (PT), na figura do governador Jacques Wagner.

\section{À guisa de conclusões: a Nova República e seu legado pós anos 1990}

No cenário da década de 1990, ainda que a democracia tenha sido amplamente aclamada como base política do Estado de direito e da organização social, o discurso da justiça social se apresenta, estritamente, como variável do desenvolvimento econômico.

A politização do debate educacional e a sua aproximação com o projeto de construção de uma educação pública, gratuita e de qualidade para todos e em todos os níveis, que era uma característica dos anos 80 , deixa de ter o mesmo ímpeto para dar lugar a formulações "menos políticas" e mais instrumentais, com ênfase na qualidade, na eficiência e na equidade. Desde então, transformar o ensino fundamental de "Máquina de fazer Fracassos" em "Máquina de fazer Sucesso", como defende Nogueira (1993), transformou-se no carro chefe das políticas educacionais assumidas pelos governos que se sucederam.

Tais mudanças, certamente, não cabiam no governo da Nova República, mas os efeitos produzidos por ela foram fundamentais para afirmar a crise do modo de intervenção do Estado e alavancar o desenvolvimento orientado ao mercado e a reforma fiscal como alternativas. Isto é, o desgaste político-social acumulado pela Nova República, que no seu momento final fazia tudo parecer um caos - o Estado em crise, a governabilidade em crise, o estancamento das políticas sociais e o "fim das utopias" - constituiu-se num cenário propício para golpear as organizações progressistas e, finalmente, possibilitar à classe dirigente que desse dois passos à frente. Não de uma só vez, mas de forma progressiva desde o governo Collor. Certamente que olhando para os elementos trazidos por Dreifuss (1989) a referência a este ou aquele governo deve ser lida da forma ampliada, pois não se trata de imputar ao Estado stricto sensu toda engenhosidade de produção e reprodução de relações de poder. A presença e a direção política dada pelos empresários não podem ser percebidas como expressões menores de um embate de projetos de poder que envolvem diferentes organizações da sociedade civil, bem como a sociedade política.

A forma como os arautos das "novas" concepções sócio educacionais se colocaram frente aos problemas educacionais correntes ilustram bem isso. Guiomar Mello (2000), por exemplo, opõe claramente a politização dos debates educacionais experimentados em contextos anteriores ao encaminhamento de um projeto educacional contemporâneo. Ela assinala que diante das transformações operadas no mundo,

talvez seja possível levantar a hipótese de que, se ao longo deste século as demandas sociais passaram por um processo de politização crescente, o terceiro milênio vai requerer que o exercício da cidadania e o encaminhamento das demandas sociais se qualifiquem tecnicamente (MELLO, 2000, p. 35).

Sob esse ideário "neo técnico" uma gama de propostas com foco na reprodução das relações capitalistas de produção se expandiram no contexto pós anos 1990, a começar pelo ajuste na Constituição de 1988 (o que no âmbito educacional resultou, entre outras, na Emenda Constitucional $n^{\circ}$ 14/96) e a finalização do desenho da própria Lei de Diretrizes e 
Bases da Educação (Lei 9394/96), a qual vinha sendo gestada desde a Constituinte. Com a aprovação desses instrumentos legais foram produzidas alterações significativas no conjunto das conquistas já consagradas na Constituição, marcando a revisão da agenda político-social da Nova República e a viabilização das reformas do Estado e da educação, por conseguinte.

$\mathrm{Na}$ educação, Oliveira (2000) sintetiza essas mudanças em termos de um movimento de redimensionamento da polaridade centralização/descentralização, no qual se promove a descentralização da gestão e do financiamento, ao mesmo tempo em que é centralizado o processo de avaliação e controle do sistema. Esse movimento, embora adquira contornos próprios no Brasil e nos países subdesenvolvidos, reserva grande afinidade com as experiências de países como os estudados por Levin (2001), a saber, Estados Unidos, Canadá, Inglaterra e Nova Zelândia.

No estudo em que esse autor descreve e analisa as mudanças nas políticas educacionais nesses países, são realçados como aspectos comuns das estratégias adotadas para a implementação das reformas: a) racionalização da administração das escolas, mediante descentralização administrativa com inserção dos pais e/ou outros membros da comunidade na gestão escolar; b) generalização da avaliação como forma sistêmica de controle; c) naturalização da concorrência entre os estabelecimentos educacionais, sob a suposição de que o "market" do sistema é inevitável para torná-lo mais eficiente e d) implementação de sistema de voucher.

As reformas, nesse cenário, constituem uma das formas de materialização do chamado processo de globalização. Nesse contexto tem-se constatado que houve trocas substantivas na formulação e implementação das políticas educacionais e que os governos adotaram a concentração das decisões como estratégia de gestão, em detrimento das práticas de negociação política (LEVIN, 2001).

No Brasil o tempo das reformas educativas balizadas por essas mudanças começa a se efetivar na década de 90, com o presidente Fernando Collor de Mello, quando o discurso da reconstrução nacional toma força sob o signo do desenvolvimento orientado ao mercado e da reforma fiscal. É o tempo da proclamação da crise do Estado e da defesa incisiva da sua reforma como condição de governabilidade e de governança, entendidas como "a legitimidade e a capacidade financeira e administrativa de governar" (BRESSER PEREIRA, 1996, p. 20).

O autor defende que a formulação da concepção da crise do Estado e a subsequente defesa de reforma administrativa são anteriores ao governo do presidente Collor, marco da implementação da agenda neoliberal no Brasil. Esforçando-se para diferenciar as abordagens neoliberal e social-liberal, aquele autor data o processo de afirmação das ideias em questão do final de 1987, quando o Plano Cruzado começou a degringolar. Diz Bresser Pereira:

A abordagem social-liberal da crise do Estado começou a se afirmar entre a esquerda moderada depois que o fracasso do Plano Cruzado demonstrou o esgotamento definitivo da estratégia nacionaldesenvolvimentista. Atualmente, ela é a alternativa real ao neoliberalismo, já que a esquerda tradicional continua presa ao nacionaldesenvolvimentismo. A interpretação da crise do Estado e a interpretação neoliberal e suas respectivas estratégias são internacionalistas, mas a primeira está baseada no pressuposto da existência de interesses internacionais comuns, enquanto a segunda está baseada no princípio do interesse nacional (1996, p. 34-35). 
Na impossibilidade política de sustentar esse projeto ainda na Nova República, Collor cumpriu a tarefa histórica de fazê-lo, abrindo um combate anti Estado nacionaldesenvolvimentista.

Vale lembrar que, antes de Collor, se vivia no país não só um momento de abertura política, mas também de efervescência e mobilização social intensa, caracterizando um momento de confronto à já histórica exacerbação da sociedade política brasileira e de fortalecimento da sociedade civil, inaugurando um momento novo nas relações de poder, o qual exigia novas formas de intervenção organizada da classe dominante em face da mobilização dos setores populares.

Como se procurou demonstrar até aqui, os movimentos político-sociais que envolvem a passagem da Nova República à democratização são emblemáticos do processo de rearticulação do plano de produção da classe dominante e a constituição da sua hegemonia, revestida dos vieses reformistas que embalaram as décadas de 1990 e 2000.

Se os anos 80 foram marcados por grande esforço de mobilização e de participação da sociedade civil nos rumos políticos e sociais do país, os anos 90 são marcados por um processo de intenso enfraquecimento das instituições, desmobilização política e a promoção de um novo "realismo político" que desqualifica ideais e valores antes tidos como pontos convergentes para a construção da democracia.

No lugar das máximas da igualdade de oportunidades, da participação e do desenvolvimento com justiça social, passam a ser dominantes as concepções de Estado que celebram a desregulamentação dos fluxos financeiros, a redução das proteções sociais e as responsabilidades individuais. Ademais, como observa Oliveira (2000, p. 80),

[...] o grande trunfo das reformas implantadas nos anos 90 é a possibilidade incorporar pontos anteriormente defendidos pelos progressistas, re-significando-os dentro de uma nova lógica. Esta peculiaridade faz com que a oposição às propostas hegemônicas seja muito difícil, pois pontualmente, podem ser defensáveis ou até mesmo reivindicações "progressistas" dos anos 80, como por exemplo, as propostas de eleições de diretores, autonomia da escola e promoção automática ou adoção de ciclos de aprendizagem em substituição ao sistema seriado, explicitamente incorporado ao texto da LDB ou facultado por ele.

Nesse cenário saltam aos olhos os precedentes criados no período da Nova República quando, embora a dialética pressão/negociação empurrasse o Estado para uma constante reorganização do poder, fazendo-se notar a eclosão das reivindicações populares, jamais houve indefinição de rumos por parte das classes dominantes. É certo que houve um tempo de mobilizações simultâneas de diferentes segmentos organizados da sociedade, mas a classe dominante fez o que pode para não perder o controle da transição e sempre soube o que queria dela e aonde queria chegar. Era necessário se reorganizar e a Nova República parece que cumpriu bem essa tarefa.

Nessa conjunção tensa de disputa da direção política da sociedade, as velhas raposas levaram a melhor. Assim parece mais adequado inferir que o esgotamento da ditadura civil militar vivida no Brasil no período 1964-1985 gestou uma transição em que a manutenção de antigos quadros políticos no controle estatal representou não apenas uma manobra política de grande engenhosidade, mas um salto dos setores dominantes na produção de um cenário de construção de consensos ideológicos afinados com o projeto de Revista HISTEDBR On-line, Campinas, $n^{\circ}$ 55, p. 34-53, mar2014-ISSN: 1676-2584 49 
reprodução do status quo. Neste cenário, a suposta "conversão" do país do autoritarismo à democracia soa fugaz como parte de um movimento complexo que, contraditoriamente, desembocou no fortalecimento dos setores empresariais e na construção de um "realismo político" que tem na negação de políticas sociais de amplo espectro o seu corolário. Portanto, a ressiginificação das reivindicações progressistas que se fortaleceram na década de 1980 minou o projeto de "conversão" democrática combinada com justiça social.

$\mathrm{O}$ que de longe parecia ser um movimento de recuo da classe dirigente, aparentemente implicada no projeto de mudança social ensejado na Nova República, de perto se revela como a necessidade de dar um passo atrás para, em seguida, dar dois à frente. A atitude de "agente interessado" na justiça social foi fundamental para reagregar as forças dominantes e garantir a continuidade do seu projeto de classe, num patamar distinto, em que a adesão política à propalada globalização se materializou como ampliação da subsunção ao capital. A intervenção legislativa do Estado, associada à força e presença das organizações corporativas nos governos, assim como a intensificação das ações organizadas de organismos representativos dos interesses políticos, da cultura e dos valores que dão sustentação ao capital findaram por introduzir na vida social modificações que asseguraram o "plano de produção" da classe dominante em diferentes níveis do tecido social, caracterizando uma espécie de "revolução passiva" que conduziu a certo esvaziamento das lutas sociais e, o mais grave, de princípios como igualdade e justiça social. Nesta lógica a educação é uma ferramenta que expande a produtividade do mercado e este "senhor" constitui a baliza do trabalho pedagógico, da organização da gestão e da visão de futuro para a vida em sociedade. Ironicamente, justo na chamada sociedade do desemprego, esta visão enfatiza a educação como chave para o enfrentamento das transformações no mundo do trabalho (flexibilidade, iniciativa, sobrevivência num mundo de incertezas). Na contramão dessa visão é vital a defesa da educação como atualização histórica dos homens e mulheres e meio de dotá-los de elementos culturais necessários para viver em sociedade (PARO, 2001).

\section{REFERÊNCIAS}

ALVES, M. H. M. (1987). Estado e oposição no Brasil (1964-1984). 4. ed. Petrópolis: Vozes.

APLB - Associação dos Professores Licenciados da Bahia (1985). Chega de angústia na educação. Salvador: APLB, 1985, 5 p. (mimeo).

BRESSER PEREIRA, L. C. (1996). Crise econômica e reforma do Estado no Brasil: para uma nova interpretação da América Latina. São Paulo: Editora 34.

CAMARGO, A. (1989). As dimensões da crise. IN: CAMARGO, Aspásia e DINIZ, Eli (Orgs.). Continuidade e mudança no Brasil da Nova República. São Paulo: Vértice, Editora Revista dos Tribunais (20-56 p.).

CONSELHO ESTADUAL DE EDUCAÇÃO. Parecer CEE $\mathbf{n}^{\circ} \mathbf{0 1 3}$, de 21 de janeiro de 1991. Aprova medidas relacionadas ao Plano Decenal de Educação (Plandeba) como sugestão à Secretaria da Educação do Estado da Bahia. Salvador, 1991, p. 6. 
CONSELHO ESTADUAL DE EDUCAÇÃO (1990). O ano letivo de 1990. Tribuna da Bahia, Salvador, 23 nov.

DEFICIÊNCIA DA EDUCAÇÃO GERA PROTESTO DE ALUNOS (1990). A Tarde, Salvador, 22 ago. Caderno 1, p. 3.

DINIZ, E. (1997). Crise, reforma do Estado e governabilidade: Brasil 1985-95. Rio de Janeiro: Fundação Getúlio Vargas.

DREIFUSS, R. (1989). O jogo da direita. 2a ed. Petrópolis, RJ: Vozes.

FONTES, Virgínia (2006). Sociedade civil no Brasil contemporâneo: lutas sociais e luta teórica na década de 1980. In: LIMA, J. C. F.; NEVES, L. M. W. (Org.). Fundamentos da educação escolar do Brasil contemporâneo. Rio de Janeiro: Fiocruz/EPSJV.

GOMES, J. C. T. (2001). Memórias das trevas: uma devassa na vida de Antonio Carlos Magalhães. São Paulo: Geração Editorial.

FAUSTO, B. (1996). História do Brasil. 4ª ed. São Paulo: EDUSP.

FIORI, J. L. (1995). Sobre a crise do Estado brasileiro. IN: Em busca do dissenso perdido: ensaios críticos sobre a festejada crise do Estado. Rio de Janeiro: Insight.

GERMANO, J. W. (1994). Estado militar e educação no Brasil (1964-1985). $2^{\mathrm{a}}$ ed. São Paulo: Cortez.

GRAMSCI, A. (1999). Cadernos do cárcere. Rio de Janeiro: Civilização Brasileira, vol. 1 (Introdução ao estudo da filosofia; A filosofia de Benedetto Croce).

(2000). Cadernos do cárcere. Edição e tradução de Carlos Nelson Coutinho. Rio de Janeiro: Civilização Brasileira, vol. 3 (Maquiavel: notas sobre o Estado e a política).

KUENZER, A. Z. (1996). Política educacional e planejamento no Brasil: os descaminhos da transição. In: KUENZER, Acácia Z.; CALAZANS, Maria Julieta Costa e GARCIA, Walter. Planejamento e educação no Brasil. $3^{\mathrm{a}}$ ed. São Paulo: Cortez.

LEVIN, B. (2001). Reforming education: from origens to outcomes. New York: Routledge Falmer.

MELLO, G. N. de (2000). Cidadania e competitividade: desafios educacionais do terceiro milênio. $8^{\mathrm{a}}$ ed. São Paulo: Cortez.

MOISÉS, J. A. (1989). Dilemas da consolidação democrática no Brasil. IN: e ALBUQUERQUE, J. A. Guilhon (Orgs.). Dilemas da consolidação da democracia. Rio de Janeiro: Paz e Terra. 
NOGUEIRA, M. J. Todos pela educação no município: um desafio para cidadãos. Brasília, UNICEF/CECIP, 1993.

OLIVEIRA, F. (2001). A nova hegemonia da burguesia no Brasil dos anos 90 e os desafios de uma alternativa democrática. In: FRIGOTTO, G. e CIAVATTA, M. (orgs.). Teoria e educação no labirinto do capital. Petrópolis, RJ: Vozes.

OLIVEIRA, R. de (2000). Reforma educativas no Brasil na década de 90. IN: CATANI, Afrânio M. e OLIVEIRA, Romualdo P. de (Orgs.). Reformas educacionais em Portugal e no Brasil. Belo Horizonte: Autêntica.

PALUMBO, D. J. (1989). A abordagem de política pública para o desenvolvimento político na América. IN: INSTITUTO DE RECURSOS HUMANOS JOÃO PINHEIRO. Política de capacitação dos profissionais da educação. Belo Horizonte: FAE/IRHJP.

PARO, V. H. (2001). Escritos sobre educação. São Paulo: Xamã.

PIRES, W. F. (1987). (Discurso de posse do governador). Diário Oficial. Salvador, ano LXXI, n 13.544, 16 mar. Caderno 1, p. 14, 15 e16.

PROGRAMA DE 100 DIAS (1987). Diário Oficial. Salvador, ano LXXI, nº 13.557, 31 mar. Caderno 1, p. 4,5 e 6. (Governador Waldir Pires).

SECRETARIA DE EDUCAÇÃO DO ESTADO DA BAHIA (1988). Alguns indicadores da situação educacional do estado da Bahia. Salvador: SEC/ IAT. (parte integrante do PLANDEBA)

(1990). Plano Decenal de Educação - PLANDEBA. Salvador: Secretaria da Educação: Instituto de Estudos e Pesquisa em Educação Anísio Teixeira.

SHIROMA, E. O.; MORAES, M. C. M. de; EVANGELISTA, O. (2000). Política educacional. Rio de Janeiro: DP\&A.

SILVA, A. A. As políticas públicas para a educação básica na Bahia nos anos 90: propostas e ações nas gestões de Antonio Carlos Magalhães e Paulo Souto (19911998). 2007, 243 f. Tese de doutorado, Universidade de São Paulo, São Paulo, 2007.

SKIDMORE, T. (1988). Brasil: de Castelo a Tancredo. 5. reimpressão. Rio de Janeiro: Paz e Terra.

Notas

\footnotetext{
${ }^{1}$ Versão preliminar deste texto foi apresentada X Jornada do HISTEDBR, no período de 26 a 29 de julho de 2011. Parte dos dados apresentados integra a tese de doutorado da autora.

${ }^{2}$ Professora Titular da UEFS, atuando na área de políticas educacionais nos cursos de licenciatura e no mestrado em educação. Contatos: antoniasilv@gmail.com
} 
${ }^{3}$ O Ato Institucional n. 2, de 27/10/1965, estabeleceu em seu artigo 18: "ficam extintos os atuais partidos políticos e cancelados os respectivos registros". A partir daí foram criados a ARENA (Aliança Renovadora Nacional) e o MDB (Movimento Democrático Brasileiro). O primeiro era o partido governista e o segundo o da oposição. Uma das ações em direção a abertura política foi a restauração do multipartidarismo, com a Lei 6.767/1979, Lei Orgânica dos Partidos Políticos, de 20/12/1979. Essa Lei extinguiu os partidos e definiu critérios e prazos para criar e legalizar novos partidos. A ARENA reagrupou-se como PDS (Partido Democrático Social) e o MDB como PMDB (Partido do Movimento Democrático Brasileiro). Cf. Alves, Maria Helena Moreira. Estado e oposição no Brasil (1964-1984). 4ª ed. Petrópolis: Vozes, 1987; Ato Institucional $n^{\circ}$ 2, de 27 de outubro de 1965. In: Constituições do Brasil: de 1824, 1891, 1934, 1937, 1946 e 1967 e suas alterações. Brasília: Senado Federal, Subsecretaria de Edições Técnicas, 1986; Skidmore, Thomas. Brasil: de Castelo a Tancredo. Rio de Janeiro: Paz e Terra, 1988.

${ }^{4}$ A Aliança Democrática constitui-se na frente política que reuniu diferentes partidos para concorrer à Presidência da República no Colégio Eleitoral em 1984 e que resultou na vitória de Tancredo Neves. Sua composição era heterogênea e ia desde o PMDB até dissidentes do PDS, entre outros partidos. Cf. Skidmore (1988).

${ }^{5}$ Skidmore indica que a comissão foi constituída em agosto de 1985 e apresentou o relatório em maio de 1986, o qual foi publicado no ano seguinte pela editora Paz e Terra, sob o título: Brasil 2000: para um novo pacto social. Antes desse relatório Jaguaribe et. al publicou um estudo tocando em muitos dos mesmos tópicos do documento referido acima. Trata-se da pesquisa Brasil, sociedade democrática, iniciada em junho de 1983 e concluída em agosto de 1984. Esta pesquisa, também coordenada por Hélio Jaguaribe, foi assinada por Francisco Iglésias, Wanderley Guilherme dos Santos, Vamireh Chacon e Fábio Comparato e foi empreendida pelo Instituto de Estudos Políticos e Sociais, com parcial cobertura dos custos pelo FINEP e pelo Banco do Estado de São Paulo. O resultado deste trabalho foi publicado pela Editora José Olympio, 1985, coleção Documentos Brasileiros, incluindo textos assinados pelos respectivos autores e referências críticas produzidas por outros intelectuais.

${ }^{6}$ Para um aprofundamento sobre o tema da educação na Constituinte Cf. Oliveira (2000) e Fávero, Osmar (org.). A educação nas Constituintes brasileiras (1823-1988). Campinas, SP: Autores Associados, 1996.

${ }^{7}$ Refiro-me ao modelo de Estado desenvolvimentista assumido no Brasil que, ao contrário dos países capitalistas centrais, "não propicia as condições de reproduções sociais da totalidade da força de trabalho nem assume a responsabilidade pelos marginalizados. Nesse sentido, em vez do Estado de bem-estar social, o que temos é uma combinação permanente e alternada de paternalismo e repressão. O que, se bem não impede que toda a população tenda a estar imersa no mercado capitalista, o faça como consumidora marginal dos seus produtos materiais e culturais, incluída aí a aspiração ao bem-estar e ao conforto, próprios de um capitalismo desenvolvido. Mas nunca na condição de população trabalhadora, com todas as suas implicações sócioeconômicas, nem na condição de cidadã, todas as suas implicações político-ideológicas” (FIORI, 1995, p. 46, grifos no original).

${ }^{8}$ Os demais ministros a que se refere o autor eram: José Aparecido, Renato Archer, Aluísio Alves e Renato Gusmão.

9 A criação da Escola Parque foi inspirada nos ideais da Escola Nova e constitui-se como modelo para a educação baiana.

10 UNESCO - Organização das Nações Unidas para a Educação, a Ciência e a Cultura; UNICEF - Fundo das Nações Unidas para a Infância; PNUD - Programa das Nações Unidas para o Desenvolvimento.

${ }^{11}$ Expressão usada por Christopher Norris para caracterizar a era neoliberal na Inglaterra e reproduzida por Shiroma, Moraes e Evangelista (2000).

Recebido em abril-2014

Aprovado em maio-2014 